This item was submitted to Loughborough's Institutional Repository (https://dspace.lboro.ac.uk/) by the author and is made available under the following Creative Commons Licence conditions.

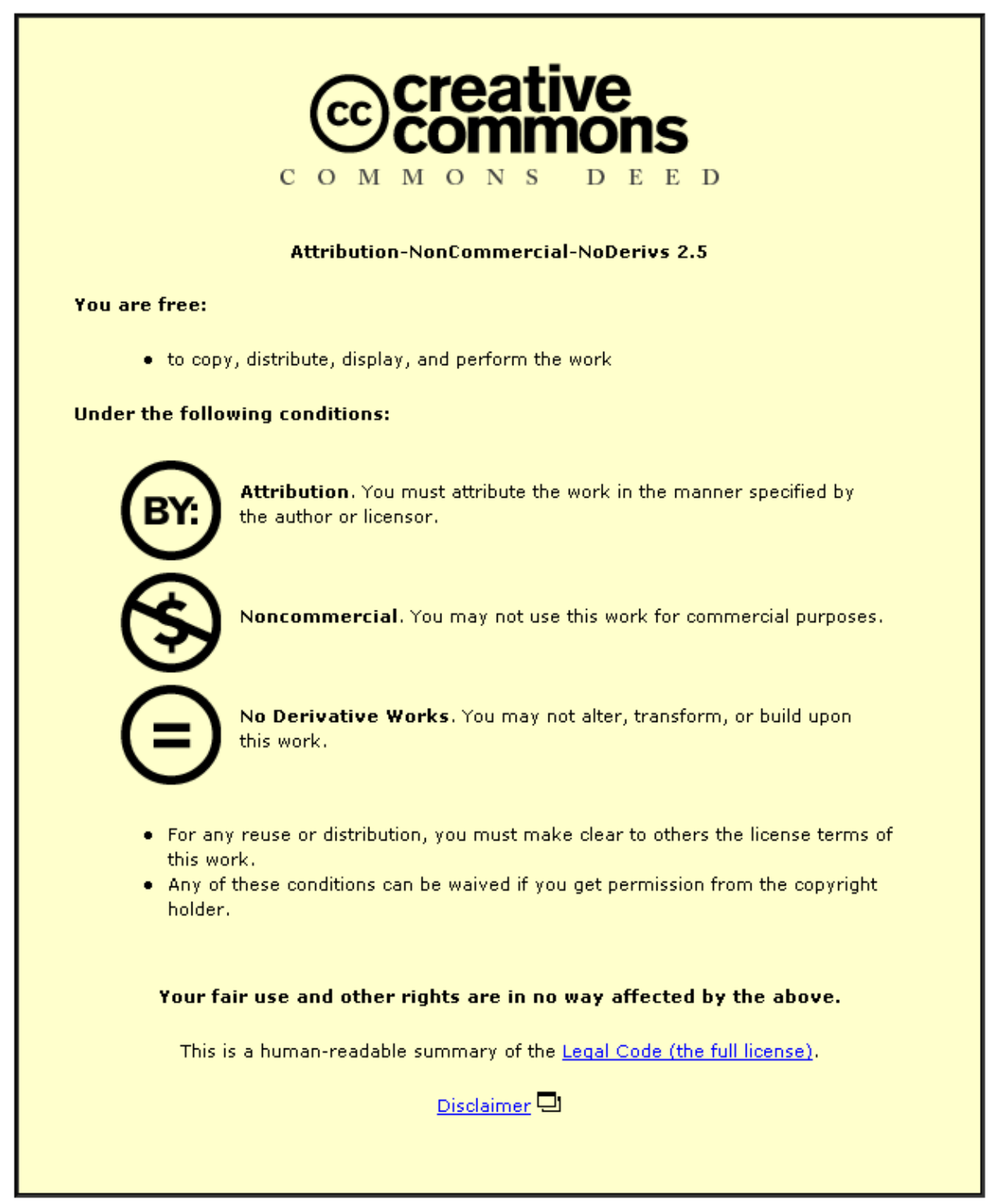

For the full text of this licence, please go to: http://creativecommons.org/licenses/by-nc-nd/2.5/ 


\title{
Mathematics Teaching Development as a Human Practice: Identifying and Drawing the Threads.
}

\author{
Barbara Jaworski \\ Mathematics Education Centre \\ Loughborough University, \\ Loughborough \\ UK \\ b.jaworski@lboro.ac.uk \\ tel: +441509228254 \\ Fax: +441509228211
}

The didactic triangle links mathematics, teachers and students in a consideration of teaching-learning interactions in mathematics classrooms. This paper focuses on teachers and teaching in the development of fruitful learning experiences for students with mathematics. It recognises primarily that teachers are humans with personal characteristics, subject to a range of influences through the communities of which they are a part, and considers aspects of teachers' personhood, identity and agency in designing teaching for the benefit of their students. Teaching is seen as a developmental process in which inquiry plays a central role, both in doing mathematics in the classroom and in exploring teaching practice. The teacher-asinquirer in collaboration with outsider researchers leads to growth of knowledge in teaching through development of identity and agency for both groups. The inclusion of the outsider researcher brings an additional node into the didactic triangle.

\section{A FOCUS ON TEACHERS AND TEACHING}

Within any setting with its particular political and institutional factors which afford or constrain activity, it is the teacher with her pupils who make the classroom what it is. While teaching-learning or teaching-for-learning, with students at the centre of all considerations of teaching and learning, has become widely acknowledged (e.g., Bartolini Bussi, 1998; Sutherland, 2007), it is the teacher who has the knowledge (although not always the power - e.g., Lerman 1996) most overtly to influence classroom processes.

In her thesis, "Bringing Teachers to the Centre Stage”, Rita Nolder (1992) reported on a study of the ways in which mathematics teachers thought about and constructed their teaching. The teacher as a person stood out in her accounts with the characteristics of each teacher seen as a part of the overall complexity in which their teaching was composed. This has been true for many other accounts in the literature since then, for example, Melvin Wilson and Michael Goldenburg (1998) wrote about "Mr Burt" who despite making considerable efforts to reform his teaching such as letting his students explore and work cooperatively, "still insisted on telling many of the important points, emphasizing what he considered to be correct ways to think about things” (p. 285). His students commented that Mr Burt "talks too much, and you sort of get bored" (p.286). Jeppe Skott (2001) wrote about "Christopher" a beginning teacher who demonstrated apparent conflicts between his school mathematics images and his interactions with students. Interpreting an episode in his teaching as "one in which Christopher's practice degenerated into a funelling approach that deprived students of the opportunity to learn" led Skott to recognise the wide range of educational priorities that impinge on a teacher's decisions in a particular interaction. Teachers 
Clare, Mike and Ben were central to my own research into investigative processes in teaching mathematics (Jaworski, 1994). All three struggled with their own perspectives in teaching and the ways in which these perspectives were realized in classroom settings, not always satisfying the teacher's goals. Many of their personal characteristics were implicit in my accounts of their teaching. In a later study, focusing on teaching development, personal characteristics of Sam and Jeanette ${ }^{1}$ were a central focus as I will discuss further below (Potari \& Jaworski, 2002). For each of these five teachers, inquiry-based interactions between outsider researchers and the teachers led to opportunities to recognize and discuss issues and to potential for tackling such issues in the future.

In this paper, for a special issue focusing on the Didactic Triangle in mathematics teaching-learning, I address relationships between teacher and teaching and the possibilities for teachers' growth of knowledge and concomitant teaching development arising from interactive inquiry with outsider researchers in a reflexive process. This is intended as a theoretical paper in which I draw on several research projects to highlight theoretical constructs. Thus, I am not reporting empirical research per se. My aim is to make a theoretical synthesis of concepts relating to teaching and its development and place the teacher "at centre stage". In doing so I seek a language in which to speak about the developing role of the teacher: I introduce a concept of 'personhood' and relate it to 'identity' and 'agency'. I link the didactic triangle to the teaching triad, a construct deriving from studies of teaching and subsequently extended to studies of teacher educator learning (Jaworski, 1994; Zaslavsky and Leikin, 2004). I link the value of collaborative inquiry between teachers and outsider researchers with associated theoretical concepts of community of practice (Wenger, 1998), community of inquiry and critical alignment (Jaworski, 2006). In doing so, I suggest an extension of the didactic triangle to a didactic tetrahedron.

\section{HUMAN CHARACTERISTICS - PERSONHOOD, IDENTITY AND AGENCY}

In seeking a language to talk about development in mathematics teaching and growth of knowledge for the teacher, I have focused on writings about teacher identity and associated agency. Because, in my experience, the teacher 'as a person' has always been important, I have sought to relate what we might call the 'personhood' of the teacher to constructs of identity and agency. Before mathematics enters the classroom scene, the people concerned, the teachers and students, are people. They act as individuals and as part of the cultures and communities in which they participate; relationships between the individual and community are complex.

Identity, according to Gee (2001, pp. 100-101) is "what it means to be a "certain kind of person"”. He identifies both natural and socially-related characteristics of identity, recognising affinity groups and institutional settings. For my arguments here I will discuss two ways of grouping such characteristics, 'personhood' and 'identity': personhood will include Gee's nature-identity and identity will have the more social characteristics. The Oxford English Dictionary defines personhood as "the quality or condition of being a person; esp. personal identity, selfhood". Since the term seems not to be used in mathematics education I have looked up 'personhood' in the psychology literature. For example, Heron (1992, p. 14) writes, “By ‘the person’ I mean the psyche [the human mind and its inherent life as a whole] in manifestation as an aware developing being in whom all its modes are brought intentionally into play ... an achievement - of both education and self-development”. Harré (1998, p. 6)

\footnotetext{
1 Teachers’ names here are pseudonyms.
} 
adapts the terminology of Apter (1989, p. 75) to speak of "personhood" as having characteristics as follows:

In displays of personhood, of our singularity as psychological beings, we express 'a sense of personal distinctness, a sense of personal continuity, and a sense of personal autonomy'.

It seems to me that for any professional, a teacher for example, there are bound to be aspects of distinctness, continuity and autonomy that are revealed through professional practice; that the nature of being a teacher and engaging with teaching draws on these qualities of personhood.

For Harré, notions of personhood contrast with notions of 'identity'. Identity is formed in relation to culture and community. According to Harré, a person's identity is seen widely as "not their singularity as a unique person, but the group, class or type to which they belong” (p. 6). He sees this as being the opposite of the characteristics of singularity, distinctness, continuity and autonomy: in terms of "much contemporary writing”, identity and personhood are opposites. Relating to personhood, Harré refers to three modes of 'self': a sense of one's location as a person; a sense of oneself as possessing a unique set of attributes; and the impression of his or her personal characteristics that one person makes on another (p. 4). These constructs seem to accord with Gee's nature-identity.

In my work on communities of inquiry (e.g. Jaworski 2004, 2006) I have drawn extensively on the work of Wenger (e.g., 1998) in order to root community of inquiry within the theory of community of practice as I shall discuss further below. Wenger (1998) talks of learning as "a process of becoming" (p.215). This, he claims, is "an experience of identity" (p.215), where identity "serves as a pivot between the social and the individual, so that each can be talked about in terms of the other" (p. 145); further "The experience of identity in practice is a way of being in the world" (p. 151). Wenger conceptualizes identity in terms of "belonging" to a community of practice in which participation involves "modes of belonging": "engagement”, "imagination" and "alignment” (p. 173ff). Any individual engages with practice, alongside copractitioners, uses imagination to weave a personal trajectory within the practice and aligns with the norms and expectations of the practice. Thus individual identity is defined in relation to the individual's participation in the community of practice (CoP) and of course other CoPs to which the individual belongs. I juxtapose these notions from Gee, Harré and Wenger, first, to emphasize key concepts of being human in relation to taking on a professional role such as teaching; second, to highlight the three important elements of professional human-ness, personhood, identity and agency; and third to emphasize (albeit briefly) that there are very different ways of conceptualizing the three elements.

Translating questions of identity into the dynamics of 'narratives' or 'stories', Sfard and Prusac (2005, p. 18) write about 'actual' and 'designated' identities: respectively "stories about the actual state of affairs" and "a state of affairs which ... is expected to be the case (emphasis in original). They write that "designated identities are [often] not a matter of deliberate rational choice", that "a person may be led to endorse certain narratives about herself without realizing that these are "just stories" and that there are alternatives". I suggest that the "actual" state of affairs relates closely to what I have called personhood above, and the "designated" to aspects of culture and community, of being in school and learning or coming to know, whether conscious or unconscious. However, these authors eschew notions of "personality, character and nature" as "being irrevocably tainted with connotations of natural givens and biological determinants" (p. 15), indicating that the concept of identity, "thought of as man-made 
and as constantly created and re-created in interactions between people” seems more suited to sociocultural projects.

Thus, in seeking the essence of the ideas expressed we come up against modes of expression which are powerful in their imagery. These differing modes draw our attention to relationships between personhood and identity in relation to the practice in which the individual engages. If we consider this to be teaching practice, where that practice includes the whole life of school and classroom, we can see school activity as an established community of practice in Wenger's terms. Within school activity the teacher has a job to do in teaching students. In characterizing mathematics teaching and its development, we need to consider the thinking and intentions of the teacher in choosing particular approaches to mathematics for students. Here we focus on the teacher's agency as a teacher - that is the agency of the person in acting as a teacher, taking on a teacher identity, engaging self (perhaps, in Wenger's terms, relating imagination to engagement and alignment) in interpreting the practice of teaching. Agency includes modes of action, a person's associated desires and rationales for action, and the sociohistorical and cultural influences which shape action; in terms expressed above, it draws on both personhood and identity.

Harré and Wenger speak of agency in rather different terms. Harré speaks of agentive power as "power [of the individual] to initiate action" (p.116). Wenger juxtaposes agency with knowledgeability, and suggests a dichotomy between theories of social structure that deny agency to individual actors, and theories of situated experience that emphasize agency and intentions, and address "the interactive relations of people with their environment" (p. 12-13). He suggests a middle ground, that of "learning as participation" which "takes place through our engagement in actions and interactions" and "embeds this engagement in culture and history" (p. 13). According to Wenger, knowledgeability arises through participation within a community of practice and subsequent "reification" (p. 57) of ideas and concepts within the practice. Reification involves "congealing into thingness" (p.58) - coming to see elements of participation as concepts in their own right, objects to be manipulated (I give examples below).

Ideas of agency have been informed by and quoted widely from the work of Holland, Lachicotte, Skinner and Cain (1998) who write about "a practice theory on self and identity" (a chapter heading, p. 19). Holland et al. trace psychological, anthropological and constructivist notions of self through a history of disciplinary focuses and contrasting ideologies to root their own frames on self and personhood. They write:

The relationship between cultural forms and personhood is no longer taken for granted, and as a result subjectivity is both more significant and more interesting. Persons are now recognized to have perspectives on their cultural worlds that are likely to differ by gender and other markers of social position. They are no longer considered to be unproblematically shaped by rituals and other key events of an enculturation that solely reflects cultural ideology. If public institutions and the rituals they stage are important to, but not deterministic of, subjectivity, then researchers need to address personhood directly (1998, p. 31).

These ideas are helpful in seeing the mathematics teacher both as a person with multiple (social) selves and as a practising professional whose teaching embodies those selves as well as the multiple forces (from mathematics, educational system, school culture etc) in which teaching is constituted. Such "socially powerful, cultural discourses and practices both position people [mathematics teachers] and provide them with the resources to respond to the problematic situations in which they find themselves” (1998, p. 32). Holland et al. speak of “a developing self-in-practice” (p. 
32) which accords well with what research has shown about teacher and teaching development as I will show below. They introduce the concept of "figured world" , drawing on Vygotsky's semiotic mediation and A. N. Leont'ev's “historical, socially and culturally constructed form of social (inter)action that he called activity"' (p. 41)

... a socially and culturally constructed realm of interpretation in which particular characters and actors are recognized, significance is assigned to certain acts, and particular outcomes are valued over others (p. 52).

Figured worlds can also be called figurative, narrativized or dramatized worlds, taking the form of stories or dramas by which particular events can be told, or "authored" (p.53). This fits with Sfard and Prusac's notion of designated identities, above.

Thus, in accord with the above accounts of aspects of personhood identity and agency, we can see teachers and those who work with them positioned in social and cultural worlds, acting within these worlds in relation to personal, social and cultural factors and developing alongside those with whom they interact. Holland et al. (1998) talk of "codevelopment", a metaphor to express "the dense interconnections between the intimate and public venues of social practice" (p. 270). They offer "an alternative formulation" to much of the literature on identity, one grounded in practice and activity theories and their own fieldwork and which they call "the space of authoring”(p. 271). Grounding these very abstract ideas in the worlds of mathematics learning and teaching in institutional settings, we can see a teacher as an interactive participant in worlds of mathematics, school, classroom, students and educational expectations to name a few. In placing the teacher as one of the vertices of the didactic triangle, it is essential to recognize this not just as a 'simple' positioning, but must be seen in terms of the complexities expressed above. In the next section, I start to address what this positioning can look like and its implications for making sense of developing mathematics teaching, both for individual teachers and for groups of teachers, and for the external researchers who work with them.

\section{JEANETTE AND SAM: PERSONAL CHARISMA AND DEVELOPMENTAL AGENCY}

Towards the end of the 1990s Despina Potari and I worked very closely with two teachers Jeanette and Sam, discussing issues in teaching, studying their classroom practice in teaching mathematics and trying to make sense of their practice in relation to a theoretical construct, 'the teaching triad' which I discuss further below (Potari and Jaworski, 2002, Jaworski and Potari, 2009). These teachers had been part of an earlier teaching development project (the Mathematics Teacher Enquiry Project - Jaworski, 1998) in which the teaching triad had been introduced. Both were interested in using the triad to develop their teaching further - so they used it as a developmental tool. We used it as an analytical tool in making sense of teaching.

Both of these teachers brought a personal charisma to their teaching: they exhibited good relationships with students through an overt use of their own personality and a warmth of interaction, drawing students into a dialogic approach to mathematics (e.g., Wells, 1999) and maintaining an orderly working environment in the classroom. However, their approaches to teaching and styles in the classroom were very different. They also had different teaching goals, some explicit, some more implicit which became revealed through the research. Jeanette told us that she placed a strong emphasis on student self esteem. She held the role of 'Year Head' in her school with pastoral responsibility for all students in her year group: she had followed relevant professional courses, and she worked with her colleagues on developing student selfesteem. Sam placed strong emphasis on mathematics. A good mathematician himself, 
he made clear to us that he wanted his students to engage conceptually with mathematics and that he designed tasks for this purpose. Each of the teachers used personal charisma to achieve these declared aims.

Although seeing it as “an individual trait, a matter of one’s individuality”, Gee (2001) categorises charisma as part of identity in a social sense: not something one is born with, since it takes others to recognize charisma through mutual engagement and interaction. I prefer to see it as part of the personhood of the teachers. It is a construct attributed by an outsider researcher to capture elements of the teacher's personality that are contributory to classroom interactions. On the other hand, the teachers' (conscious) decision-making on self-esteem or mathematics seems more related to figured worlds in which they participated, and can be seen in terms of their agency in teaching. For Jeanette, her focus was on encouraging her students to engage with mathematics and to have confidence in their own possibilities for success. For Sam, it was on forms of mathematical engagement and the resulting conceptual understanding that could emerge.

So we can see Jeanette or Sam placed at a vertex of the didactic triangle, linked in certain ways to the other two vertices, students and mathematics. The characteristics I have outlined above start to suggest what these relationships look like. In order to express these relationships more explicitly, the teaching triad becomes helpful. The triad is a theoretical construct with three elements Management of Learning; Sensitivity to Students, and Mathematics Challenge. It could be seen to expand the teaching node of the didactic triangle and to clarify links to the other nodes.

The three elements of the triad are deeply related, although these relationships have been seen in different ways by different teachers in relation to their own practice (Jaworski, 1994; Potari \& Jaworski, 2002). Management of learning is about the organization of the classroom, the ways students are grouped, the tasks they are offered, the kinds of interactions that are encouraged and the general ethos of human relationships. It involves the teacher in interpretation of the curriculum, institutional norms and expectations and assessment procedures. Sensitivity to students has two facets: cognitive and affective: cognitive sensitivity reflects teachers' efforts to know their students' learning and thinking styles and propensities; affective sensitivity reflects their efforts to create a respectful, inclusive and supportive learning environment in which students are able to engage cognitively. Mathematical challenge seeks to capture the ways in which mathematics is brought into the classroom and offered to interest, motivate and engage students, and promote higher levels of cognitive engagement.

Jeanette and Sam decided themselves their focus for developing teaching: Jeanette suggested she did well with regard to sensitivity, but needed to make more emphasis on challenging students to a greater degree with mathematics; Sam thought his degree of challenge was suitably demanding, but recognized that some students were resistant to his tasks and expectations, so he had to achieve more effective sensitivity.

Undoubtedly, these perspectives were related to the professional development and research worlds in which the teachers and ourselves had engaged. The teaching triad existed for them in these worlds and they brought its ideas to their respective school and classroom worlds. Interesting for us as outsider researchers were the ways in which development took place in terms of the teachers' achieving the goals they set themselves. Both teachers worked in the classroom to start to achieve these aims and we observed their teaching over a three months period. During this time we held several lengthy evening meetings at which we discussed what had taken place in the classroom and many issues relating to classroom practice in a school context within the UK educational system. As a result we had considerable observational data from 
classrooms (audio-recorded as far as possible) and audio recordings of our meetings. These were analysed through a grounded approach to reveal characteristics and issues, and then using the teaching triad to link to theory.

Analyses supported (or challenged) the teachers' own evaluations of their activity and pointed towards issues in the developmental process. For example, Jeanette's questioning of students about their findings in an investigational task showed students' corresponding development of conceptual ideas, and exemplified a pedagogic process extendable to other activities. However, within pressures of time and student distraction, she adopted a mode of telling and explaining in contrast with the inquiry base of the earlier activity and lacking much student engagement with mathematics. In Sam's case, with different groups of students we saw considerable evidence of imaginative design of inquiry-based tasks and of related questions to engage students conceptually with mathematics. However, there was also evidence, in more than one group, of students who were not comfortable with his approach and who were unable to achieve mathematically in consequence (see Jaworski, 1996; Jaworski and Potari, 2009; Potari and Jaworski, 2002)

In the above we see inter-related aspects of personhood, identity and agency in the teachers' activity and developmental process. Personal characteristics were evident in their classroom persona, ways in which they interacted with students and dealt with practical situations, and their design of tasks. These, of course, are not distinct from social elements of practice, the figured worlds in which they have engaged: ways in which they worked within institutional norms and in relation to the mathematics curriculum; relations with other professional associations in which their ideas have developed, their relationship with research projects and with us in this project. Agency seems complexly related to both personhood and identity in all of these areas. Both teachers took precious time within everyday practice to work as part of this research project which supported their own desires for developing teaching. In this they were different from many other of their teaching colleagues. Theoretical ideas in terms of inquiry-based practice and the teaching triad were addressed in ways which went beyond their everyday practice and which related strongly to the interest shown by the outsider researchers and the knowledge they brought to interactions (Jaworski, 2008). These developmental ideas will be taken further below.

\section{INQUIRY-BASED DEVELOPMENTAL PRACTICE}

Jeanette and Sam both engaged in what has been called an inquiry-based approach to learning mathematics, where inquiry involves questioning, exploring, seeking solutions, and looking critically at outcomes (e.g., Jaworski, 1994; 2006; Wells 1999). The classroom community, teacher and students, engaging together in inquiry can be called an inquiry community. The concept of inquiry community can be seen as a transformation of Wenger's community of practice in which inquiry presupposes a critical element. Thus engagement, imagination and alignment are still elements of participation, but alignment has now a critical nature - critical alignment - in which participants look critically at their practice whilst aligning with its norms and expectations (Jaworski, 2006). This can be seen in encouragement to students to ask and explore questions in mathematics and also in teachers' questioning and exploration of aspects of teaching practice. Critical alignment is a form of agency drawing on both personhood and identity.

Working with mathematics in classrooms in inquiry ways requires a perspective on mathematics as something to be created or constructed, something fallible, rather than as something absolute and pre-given (Ernest , 1991). It manifests itself in the relationship between teacher and mathematics and influences relationships between 
teacher and students and ultimately between students and mathematics. In the words of Hans Freudenthal,

It is a not so new, but still rarely fulfilled requirement that mathematics is taught, not as a created subject but as a subject to be created (1978, p. 72)

Jeanette and Sam both designed and offered tasks to engage students in inquiry and in creating their own mathematics. Such activity is perhaps not so common in mathematics teaching generally. Scandinavian professors of mathematics education, Ole Skovsmose and Roger Säljö, write about classrooms in which an exercise culture prevails.

This implies that the activities engaged in the [mathematics] classroom to a large extent involve struggling with pre-formulated exercises that get their meaning through what the teacher has just lectured about. ...

An exercise traditionally has one, and only one, correct answer, and finding this answer will steer the whole cycle of classroom activities and the obligations of the partners involved. (Skovsmose and Säljö, 2008, p.40)

The pre-formulated exercises mentioned here fit rather into a figured world of mathematics that is given and closed, that is created by others before being handed on to students - perhaps a 'pseudo' mathematics. The role of students in such a situation is to accept and make sense of, rather than to investigate or explore for themselves. The nature of classroom situations that fit with an exercise culture is rather different from those that fit with an inquiry culture. I point out the Scandinavian origins of these words to emphasize that although an exercise culture may be experienced in English schools (e.g., Boaler, 1997; Boaler \& Wiliam, 2001; Nardi \& Steward, 2003), it prevails also beyond the UK context. It is perhaps clear that teacher/teaching identities are formed and manifested rather differently in schools where an exercise culture prevails and those where an inquiry culture can be seen.

Skovsmose and Säljö write further:

The ambition of promoting mathematical inquiry can be seen as a general expression of the idea that there are many educational possibilities to be explored beyond the exercise paradigm. (2008, p. 40)

This statement has profound implications: first, that exercises are only a part of a much bigger picture where learning mathematics is concerned - lecturing and exercises, by themselves offer extremely limited "educational possibilities", even an impoverished educational environment (Pring, 2004) in which the pseudomathematics created is actually a travesty of mathematics as a broad discipline; second, that there is something here to be explored, the something being, perhaps, what these educational possibilities might consist of. And the people who do the exploring have to include those who are central to classrooms where activity can be explored - in other words the teachers and their students. We see here further dimensions of relationships in the didactic triangle. Such exploration is of course a form of inquiry, and we are talking here about a process of inquiry into teaching, or a research process. In a developmental context, the issues that are brought to the surface in order to be addressed by teachers are a significant outcome of such inquiry. Also they reveal tensions between traditional cultures of schooling and teaching, and innovative approaches designed to engage students more conceptually with mathematics. We see here alternative figured worlds. While participants are active in a clearly defined world, participation is less problematic than when their activity spans divergent worlds. Teachers can start to see how and where their best intentions (formed in the professional development research world) are challenged by 
unwelcome outcomes that fit more obviously with traditional norms (the established school classroom world). The outsider researchers engaging in participatory inquiry, supporting the teachers, collecting and analyzing data from teaching and feeding back, and offering a dialogic mode to discuss issues and address tensions, are intrinsically aligned with a critical process. They operate in worlds of theoretical ideas and translating theory into the practice of classrooms. However, they are not a part of the classroom world and do not experience practice in the ways teachers do. Their judgments on practice or interpretations of practice can be at odds with those of the teachers which presents issues for co-development.

Thus, we see the following areas of theory contributing to an expansion of the teaching node of the didactic triangle:

1) The personhood, identity and agency of classroom teachers and outsider researchers and the influences of figured worlds in which they are active;

2) The teaching triad, expanding on teaching roles and highlighting characteristics and issues in teaching;

3) Inquiry-based approaches to mathematics in the classroom and to developing the teaching of mathematics;

4) Relationships between teachers and mathematics educators in participatory research/inquiry to achieve critical alignment.

I elaborate on these four areas of theory in a further example taken from inquiry-based approaches to developing teaching.

\section{LEARNING FROM AN INVESTIGATIONAL APPROACH TO MATHEMATICS IN THE CLASSROOM}

\subsection{A classroom episode}

The design of mathematical activity for the classroom links teacher and mathematics in a didactical process. The teacher has to start from abstract mathematics in the area of a topic (perhaps suggested by the curriculum) and design activity for students through which they will gain access to and come to understand the topic. The design will include tasks to engage the students with mathematics (didactics) and modes of activity to support their engagement (pedagogy). This example comes from my analysis of data from the classroom of a teacher, George, who used investigational tasks with his 12-year-old students (Jaworski, 2011). Parts of the lesson analysed were included in a published videotape (Open University, 1988).

The teacher's didactic goals might be described as follows

- To provide opportunity for students to engage with the topic;

- To stimulate language patterns and imagery to contribute to understanding;

- To provide a need to practice and apply procedures - not just practice for its own sake;

- To promote students’ own exploration and inquiry for motivation and purposeful engagement.

George was working with students within the mathematical topic of area and perimeter and had chosen a task in which students were asked to work out and explore perimeters in a given scenario, and to generalize from their observations in terms of some mathematical rule or formula. Students worked in friendship groups on a given basic question and came up with their own questions and ways of tackling them. Analysis of the dialogue from three girls in one group showed evidence of their 
engagement with the task, of trying out special cases and seeking patterns, and of conjecturing and generalizing from conjectures (e.g., Mason, et al., 1982).

The teacher had chosen a task named "Four square perimeter". It was stated simply as follows:

What perimeters can we get with four squares placed edge to edge or corner to corner, but not overlapping? (5? 6? 10? 99?)

Two examples of legitimate arrangement of the four squares can be seen in Figure 1.
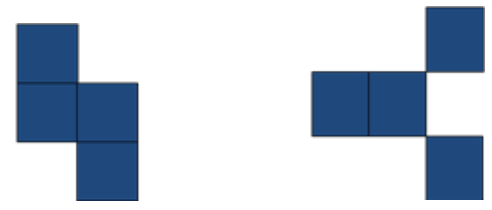

Figure 1: Ways of arranging four squares

The class had worked on the task, trying out different arrangements and different numbers of squares as suggested in the question. In all cases, according to the rules of arrangement, the perimeter they found was an even number. This resulted in a conjecture, "the perimeter will always be even", and led to a question, "is it possible to find an odd perimeter?”

I focus now on a video-extract of three girls' approach to tackling this question. In discussion with the teacher they had suggested that, rather than lining the squares up with full sides touching, they might consider the situation with half squares touching. They talked about and drew various diagrams, and then one girl offered the diagram in Figure 2 and started to count its sides.

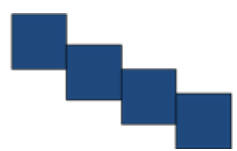

Figure 2: Four squares with half sides touching

The other girls joined in the counting. They counted sides in the perimeter and counted again. It seemed to add up to 13 . They then counted systematically together all the whole sides first (there were 10) and then the half sides (6), so altogether 13 sides - a perimeter of 13 . One of the girls said, "So you can. If you take half squares you can get an odd number", and the other two nodded in agreement. We then see the teacher return to this group and the girls eager to tell him what they had found. The girls spoke all at once "you can ... ", "if you add the half squares (sic) ...", "you can get an odd number". The teacher looked at their diagram and started to count: one, two, two-and-a-half, ...”. "No" said the girls, "No, No, count like this", and they demonstrated their systematic form of counting. The teacher followed their instructions; he counted 10 whole sides, wrote down 10; he counted the half sides, wrote down 3, then he wrote 13, and said "Hey!”. The "Hey” seemed to acknowledge their success. They were all smiling and seemed pleased with themselves.

I have described this episode in detail to acknowledge certain aspects or qualities of this lesson. The girls were fully engaged in their investigation: there was an unforced spontaneity in their words and actions, their faces were animated and they seemed to enjoy the activity. They wanted to be sure of what they were finding as shown through their drawing and redrawing their figures and checking and rechecking their counting. They bounced ideas off each other through half-formed sentences. When the teacher returned to them, they were insistent that he should do the counting in their way telling him clearly what to do. This demonstrated a confidence in their finding that an odd number was indeed possible with this kind of arrangement. 
In terms of what was achieved in this lesson, we might say that these students knew perimeter - that perimeter, for them, had been 'reified' (Wenger, 1998). They could count it, talk about it, work with it and manipulate it. They showed evidence of mathematical thinking: of trying out special cases, making conjectures and moving towards generalisation (e.g., Mason, et al., 1982). They worked well together within a group, built on each other's suggestions, and looked critically at what they had found. We could argue that all they had found was one special case. We did not see them check other numbers of squares. However, their systematic mode of counting could be seen as generic. We might believe they could have applied this to any number of squares. The teacher did not push them to check further. In fact they had answered the question, "is an odd number of sides possible?” The answer was "yes".

\subsection{The teaching community}

The teacher George was one of a team of mathematics teachers in the mathematics department of their school. I was working as a researcher with several of them as part of my PhD research. It was common for us to sit together to view a video episode from a lesson and discuss aspects and issues in teaching (Jaworski, 1990). Usually the teacher in the video started discussion with reasons for choosing the particular episode. George chose and introduced the episode I have referred to above. He described the setting and the task, we watched the video recording and he then reflected on his experience. He referred particularly to a part of the girls' activity in which they had invented a novel approach to their problem which both girls and teacher called the "half-squares" approach. George acknowledged that he had not thought about this before but had encouraged the girls to go further with their approach. He said,

I was ad-libbing - I didn’t know what would happen for half squares.

These girls were teaching me something.

It appeared that, in encouraging the girls to explore further with the half squares, the teacher was on unknown ground, but willing to take a risk; perhaps, later, in using this task with other students he would be more aware of possibilities and able to judge whether to push towards them. He seemed to have learned from the girls' activity and reasoning, thus overtly developing his teaching. In acting himself in inquiry mode, trying out possibilities in his classroom and learning from outcomes, he increased his own knowledge of teaching.

While respectful of George's activity and decisions as a teacher, the other teachers probed teaching decisions and outcomes. One issue, raised by one of George's colleagues, was a challenge to friendship groups, suggesting they might be too "comfortable" and possibly not challenging enough. This was debated in the group, with George and his colleague finally choosing to disagree. George said, "even at my age, I do better when I am working with my friends”.

There was some agreement among the teachers as to what activity with this task had afforded, in encouraging students' meaningful engagement with mathematics:

- They engaged actively with the topic and with mathematical process and seemed to be enjoying themselves

- They asked questions and explored possibilities

- They practised finding perimeter and seemed to have a good grasp of both how to find it and what it meant.

They did not go on to justify their conjectures more generally or to find any kind of proof. This might be seen as something to work on more overtly in the future. Thus, 
through working investigatively with his students, the teacher also learned. Through working with his colleagues and a researcher he had the chance to develop didactical/pedagogical knowledge, such as an awareness that friendship groups might not be the only way to organise his students, or that it might be worth pushing students more overtly towards generalisation and proof.

\subsection{The didactic triangle and the teaching triad}

Applying the teaching triad to the lesson described above, I can characterize the teaching as follows.

Management of learning: Organizing the classroom in friendship groups, encouraging students to choose their own groups and where and how they would sit together. Choice of task on which the class would work, and the mode of delivery of task to class. Organization of small group and whole class elements of activity. After initial work in small groups a whole class sharing of results led to a class conjecture and further questions relating to that conjecture.

Sensitivity to students: Organizing the classroom in friendship groups, encouraging students to choose their own groups and where and how they would sit together. Moving between small group and whole class activity to value the findings of the group and allow all members of the class access to what different groups had found. We might call the former affective sensitivity and the latter cognitive sensitivity (Potari and Jaworski, 2002). Choice of a task that is readily understandable by all students to provide ease of access to mathematical ideas might be seen to have elements of both affective and cognitive sensitivity.

Mathematical Challenge: The task itself - easily understandable and accessible for all students, but with potential for exploration in a range of directions relating to the topic of perimeter. Encouragement of the use of a variety of mathematical processes. Teachers' questions to the students and his suggestions or challenges for their interaction with the task.

It can be seen that Management of Learning, creating the learning environment involves a teacher in both didactical and pedagogical choices. There are of course many other possibilities for the choice of tasks to engage students with ideas of perimeter. This task appeared to be valuable in providing ease of access, possibilities for exploration, opportunity to engage with mathematical processes and to achieve knowledge and understanding of perimeter. Similarly there are many ways of organizing the classroom. George was challenged by his colleagues to rethink his use of friendship groups, or at least to try other grouping strategies. Many of these choices relate to the teachers' sensitivity to the needs and activity of his students, both affective and cognitive; mathematical challenge in the task and teacher's interaction and questioning relate to student engagement and achievement. The extent to which the degree of challenge is appropriate to the particular students reflects an important relationship between sensitivity and challenge, referred to as "harmony" in the teaching-learning relationship (Potari \& Jaworski, 2002). We might infer here a good degree of harmony, although there are questions as to whether a higher degree of challenge might have been appropriate. In retrospect it is possible to observe that opportunity could have been taken to push students towards further generalization and proof. Discussion in the teacher group, and with an outsider researcher, allowed such issues to be aired with the possibility of increased teacher awareness relative to direct experience and activity.

We are talking fundamentally here about the teacher's agency -- what he can and does do now and what the developmental process might allow him to do in the future -- but 
it is also clear that this is closely related to his identity which links personhood to the community in which he operates as a teacher. His willingness to talk about "adlibbing" shows a confidence in his own learning process and its validity (the teacher is not supposed to know everything) and his reference to "even at my age" demonstrates personal views and characteristics. His consideration of students and care for their well-being in relation to classroom activity in mathematics relates to his personally preferred ways of interacting with others. This results, perhaps, in more emphasis on affective sensitivity that on the cognitive, whereas his colleague's focus seemed to be more towards the cognitive - focusing on which modes of classroom arrangement might lead to higher cognitive engagement and perhaps to deeper mathematical understanding in terms of generalization and proof.

\subsection{Wider infuences on teaching and its development}

In our discussion in the teacher group, teachers offered detailed information about their own students and their reasons for working with students in particular ways. They picked out episodes where they felt pleased with learning outcomes and others where they would have preferred some alternative outcome, or in retrospect would have taken another approach. This activity reflected deep levels of knowledge that inform teaching decisions. As we worked together over a period of about 6 months, it became possible to introduce and discuss areas of theory in relation to the teaching episodes we discussed. For example, we talked about processes in mathematical problem solving (e.g. Mason et al, 1982) and elements of a Vygotskian theory of learning (Jaworski 1994). This bringing together of aspects of knowledge allowed all of us to learn and expand our understandings of teaching development and hence our own professional identities.

The teachers in the group worked in a large secondary school known for its progressive approach to education (e.g., Edwards and Mercer, 1987; Boaler, 1997). Students called teachers by first names, unusual in the UK. Different classroom organizations were encouraged with regular moving of the furniture. Pairs of teachers visited each other's lessons in an activity of mutual support and observation (Gates, 1989) allowing opportunity to see other's modes of practice and discuss issues of teaching with a sympathetic colleague. The activity that I have described fitted into this environment, which was rather different from that in some other schools in which I have worked then or since.

Thus, teacher identities were formed relative to this school environment. What was possible here, or overtly encouraged here was different from some other settings. However, each teacher also demonstrated clear aspects of their own personhood. The Head of Department, Mike was undertaking a part time master's degree in education and was very keen to discuss educational issues. After observing his lessons, I was unable to remain neutral in a discussion of what had taken place because I was pressed to offer my points of view of the range of issues which emerged. Another colleague, Clare, who was taking a part time master's degree in mathematics, was very sure of her reasons for what happened in her classroom. She showed extreme knowledge of individual students and would talk about them at great length. Transcripts of our discussion showed lengthy segments from her with only brief comments or questions from myself. All of this and more detail can be found in Jaworski(1994).

I emphasize that these teachers were individuals, with individual personhood, and at the same time, they were members of the community of practice of their school. Their agency in designing activity for their classrooms and interacting with their students is related to their participation in all their communities, especially in their school community. 


\subsection{Developing teaching through shared knowledge}

The lesson described above with George and his students fits with "an investigative approach" to teaching mathematics (Jaworski, 1994). This involves a teacher in offering students situations for investigation in order to learn mathematics. In the case described, the situation involves positioning numbers of squares relative to each other, determining the perimeter so formed, and generalizing from patterns which exploration reveals. In the process of investigating this situation, students had to work with perimeters from which an understanding of perimeter, as a reified object, resulted. As part of this activity they developed their awareness of mathematics process and their ability to think and reason mathematically. We see here another example of an inquiry-based approach in which the classroom with George and his students can be seen as an example of an inquiry community. Here students inquired into mathematics, looked critically at a mathematical situation and generated mathematical relationships as indicated above. George himself explored the use of investigative activities in his classroom and learned about possibilities and outcomes. He and his colleagues used the classroom video material to raise and explore issues in teaching and learn more about investigative teaching practice. This activity involved teachers engaging overtly in collaborative reflection on their own practice, in practitioner research activity. In doing so they showed interest in developmental activity and willingness to give their time to engagement. We can see them as reflective practitioners, or more radically as practitioner researchers, actively exploring their own practices collaboratively in a process of co-development.

There are very different points of view as to whether teachers can or should take on research roles. Donald McIntyre writes:

[I]t seems unreasonable to demand of teachers that they be researchers as well as teachers, when the expertise required for the two activities is so different (1993, p. 43).

The suggestion here is that, for most teachers, engaging in research would not be a part of their teaching identity and their agency would not extend to initiating research. My own experience in working with many teachers over the years is that striving to be a good teacher is demanding enough, along with the many facets of a teachers' role within the school environment, without taking on a research responsibility. Yet, a teacher can be seen as the person best placed to take on the exploration suggested, and we see in Sam, Jeanette , George and colleagues a willingness to give extra time, interest and energy to their exploration. University researchers do not have the same knowledge of or access to students, and they certainly are not aware enough of all the constraints a school imposes on a teacher's time and energy. Yet, university researchers bring other dimensions (knowledge of theory and research, and of situations beyond the local) which make an important contribution to such research. Also, it is hard for practitioners, with identities rooted within their practice to develop a critical attitude to practice (Wells, 2001). The outsider researcher is in a better position to offer a critical perspective, to act as a critical friend, which can be possible when trusting relationships are able to be formed.

It therefore seems obvious that those people who have research knowledge and expertise should work with teachers to enable exploration of teaching and learning issues, which can be seen in action research studies in mathematics education and more generally (see e.g., Elliott, 1991; Stenhouse, 1984; Zack, Mousley and Breen, 1997). We might see the relationships between George and his colleagues and the outsider researcher to be a microcosm of such a relationship. We would not have said at the time that the teachers were engaging in research. However, they were reflecting 
deeply on their teaching practice, and on their students' activity and learning, and these reflections were feeding back into their teaching. Their students were engaging in inquiry-based activity in classrooms and the teachers were learning more about this activity as they worked together and with the outsider researcher. The same can be said of Sam and Jeanette. We might ask what personal characteristics led to these teachers' extreme motivation and energy in engaging professionally to the extent described.

For George and his colleagues teaching identity already encompassed a belief and working knowledge of inquiry-based classroom activity; teaching agency included a willingness to experiment and take risks, to reflect with colleagues and feedback to the classroom. This activity was supported by the outsider researcher who collected video material as data for analysis, made this video available for group discussion and joined in discussion and debate. Thus, teaching development and its constituents here included relationships with the outsider researcher who also has personhood, identity and agency related to university activity and other areas of experience.

\section{PERSONHOOD, IDENTITY, AGENCY AND THE DIDACTIC TRIANGLE}

In this paper I have focused on mathematics teaching development as a human practice, relating to personhood, identity and agency of teachers and their relationships with external researchers in the developmental process. I exemplified developmental practice through two cases of development and research - one conducted in the late 1980s (including the work with George and his colleagues), one taking place in the late 1990s involving Sam and Jeanette. I could have included examples from more recent research, but space was against this (see however, Jaworski, 2008). In both cases the focus of the project was on teachers' thinking and development while acknowledging that the motivating force for the teachers themselves was activity to promote the mathematical learning of their students. Teachers focused on the learning of their students, using inquiry to explore new approaches to teaching as well as inquiry-based tasks for their students' learning. In both the cases, outsider researchers, were involved, working with teachers to promote development of teaching, resulting in clear learning for the outsiders as well as for the teachers. In one of the later projects ${ }^{2}$, to avoid the term "researcher" seeming to apply only to the university people, we university researchers started to call ourselves "didacticians" - people from the university with knowledge of research and theory in the didactics of mathematics, interested to work with teachers to promote better opportunities for mathematics learning in classrooms. Here, I have shown examples from research of ways in which teachers and didacticians learned and some of the outcomes in terms of developed identity and increased agency.

In characterising the teacher/teaching node of the didactic triangle I drew on theories of the teaching triad and of inquiry community both contributing to relations with the two other nodes. We might see these areas of theory as frameworks helping us to characterise teaching, while the theoretical perspectives of personhood identity and agency help to characterise the teacher. In neither case was data collected beyond the school environment so all suggestions of personhood, identity and agency are interpretations within these limitations. However, the qualitative data collected were extremely rich allowing multiple juxtapositionings to challenge interpretations. The

\footnotetext{
2 The LCM (Learning Communities in Mathematics) Project in Norway in which a team of around 12 didacticians collaborated with up to 30 teachers from 8 schools to promote inquiry in classrooms (see e.g., Jaworski, 2008).
} 
external researcher, didactician, interacting with teachers and (we can argue) with their teaching, adds an extra dimension to the triangle.

We see, therefore, exemplification of the use of various areas of theory in conceptualising the teacher/teaching/didactician relationship and developments therein relating to mathematics learning-teaching in classrooms. To summarise, the teacher (and indeed the didactician) is a person with qualities of personhood and identities relating to professional communities. Strongly associated with both personhood and identity is the knowledge in practice which contributes to professional agency. The examples have illustrated key aspects of this knowledge and ways in which it can be seen to have grown through the activities described. In many ways these particular teachers represent their profession having many practices and qualities in common with their colleagues. In other ways they are special - here particularly in being motivated to undertake inquiry-based practice, to give time to collaboration with didacticians, and to engage seriously with reflective developmental practice. Although their knowledge in practice goes far beyond didacticians' knowledge, the complementary knowledge (of theory and research) brought by didacticians provides stimulus and inspiration to which the particular teachers are able to respond. Outstanding in all cases was evidence of increased agency for teachers who participated in the various projects. Teachers developed new approaches to working with their students and inquiry ways of being and doing in classrooms. In parallel, although not discussed explicitly above, didacticians learn fundamentally about how theories and research findings do or can influence the practice of real teachers in real schools and classrooms acting under all the constraints of institutional and political pressure. As a didactician myself, I am aware of the power of this collaborative knowledge and associated developmental practice in addressing approaches to educating students in mathematics.

Figure 3 shows a three-dimensional vision of the didactic triangle in which several teachers and their students are considered; I have included also the didacticians (D) as an adjunct to the triangle.

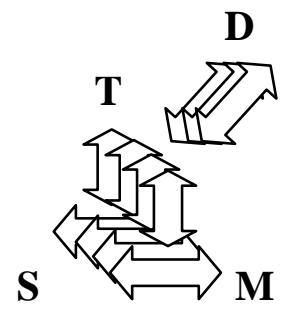

Figure 3: The didactic triangle for several teachers, their students and didacticians I emphasise here aspects of co-development relating to the views expressed by Holland et al (1998) in their discussion of figured worlds. I have shown evidence that teachers and didacticians demonstrated actively their identity and agency in relation to their own personhood and to established communities of practice of school and university. Collaboration between teachers and didacticians, in the two examples, encouraged interactive development of practices and perspectives which, through critical alignment, challenged the ways of being, the figured worlds of the established communities, and introduced new worlds with respect to which identities could develop and agency be expressed.

This version of the didactic triangle pictured in Figure 3 might be seen to capture relationships at any point in time, but it does not recognize teaching development in any obvious way, nor does it recognize elements of situation and context. In order to 
to reflect elements of learning and development for teachers and didacticians. I offer, tentatively the schematic representation in Figure 4. 


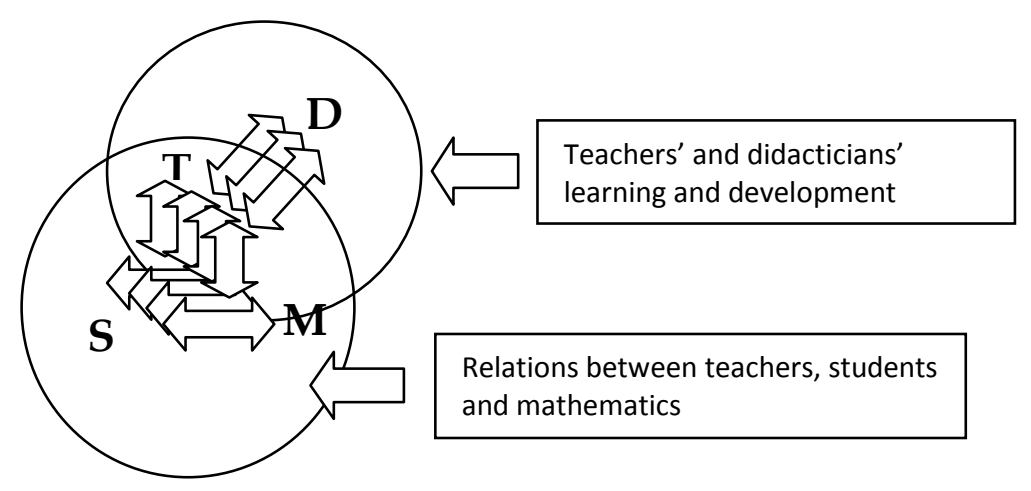

Figure 4: The expanded didactic triangle

The lower circle represents the traditional didactic triangle, relating teacher student and mathematics and seeking to capture or characterize elements of the relationships involved within a community of teachers, their students and mathematics. This includes didactical and pedagogical thinking of the teacher in translating mathematics into classroom action, the interactions between teacher and students in the classroom, the ways in which both teacher and students interact with mathematics and ways in which teachers themselves interact within the school context. It also includes elements of personhood, identity and agency with respect to teaching-learning philosophies which prevail and of the sociocultural contexts in which the mathematics classrooms are situated. All of these elements are exemplified above. The upper circle is of a different nature from the lower. Whereas the lower seeks to characterize situations, activity, events, and relationships (the situational), the upper circle represents the developmental processes which take place when teachers and didacticians inquire into everything which is characterized in the lower circle (the developmental). In this respect the upper circle represents codevelopment, a meta-dimension on the lower.

Thus we see two interacting frames which is useful in allowing us to distinguish the developmental aspects of the activity from the situational aspects. The developmental aspects as described in this paper come through a foundational focus on inquiry at the three levels within communities of inquiry in which critical alignment is one of the key elements of practice. The developmental frame provides a focus on the learning of teachers and didacticians as they participate in insider and outsider research with clear learning outcomes for both groups building on personhood and reflected in new identities and increased agency. This paper has emphasised the human nature of these participants and ways in which their changing identity and agency reveal elements of their learning and development.

\section{REFERENCES}

Apter, M. (1989). Negativism and the sense of identity. In G. Breakwell (Ed.), Threatened Identities. London: Wiley.

Bartolini Bussi, M. G. (1998). Joint activity in mathematics classrooms: A Vygotskian analysis. In F. Seeger, J. Voigt, \& U. Waschescio (Eds.). The Culture of the Mathematics Classroom. Cambridge: University of Cambridge.

Boaler, J. (1997). Experiencing School Mathematics. Buckingham: Open University Press. 
Boaler, J. \& Wiliam, D. (2001). 'We’ve still got to learn!' Students' perspectives on ability grouping and mathematics achievement. In P. Gates, (Ed.) Issues in Mathematics Teaching, pp. 77-92. London: Taylor and Francis.

Edwards, D. \& Mercer, N. (1987). Common Knowledge. London: Falmer Press.

Elliott, J. (1991). Action research for educational change. Milton Keynes: Open Univrsity Press.

Ernest, P. (1991). The Philosophy of Mathematics Education. London: Falmer Press.

Freudenthal, H. (1978). Weeding and Sowing. Dordrecht: D. Reidel Publishing Co.

Gates, P. (1989). Developing Consciousness and Pedagogical Knowledge Through Mutual Observation. In P. Woods, (Ed.), Working for teacher development. (p 11-38). London: Taylor and Francis.

Gee, J. P. (2001). Identity as an analytical lens for research in education. Review of research in education, 25, 99-126.

Harré, R. (1998). The Singular Self. London: Sage Publications.

Heron, J. (1992). Feeling and Personhood: Psychology in another key. London: Sage Publications.

Holland, D., Lachicotte, W., Skinner, D. \& Cain, C. (1998). Identity and agency in cultural worlds. Cambridge: Harvard University Press.

Jaworski, B. (1990). Video as a tool for teachers' professional development. British Journal of In-service Education, Vol 16, No. 1, 60-65.

Jaworski, B. (1994). Investigating Mathematics Teaching: A constructivist enquiry. London: Falmer Press.

Jaworski, B (1996). A study of teacher enquiry into the processes of mathematics teaching. In Proceedings of the International Group for the Psychology of Mathematics Education, 3:129-136, Valencia, Spain: Universitat de Valencia.

Jaworski, B. (1998). 'Mathematics Teacher Research: Process Practice and the Development of Teaching', Journal of Mathematics Teacher Education, Vol. 1 number 1 pp 3-31.

Jaworski, B. (2004). Grappling with complexity: Co-learning in inquiry communities in mathematics teaching development. In M. J. Høines \& A. B. Fuglestad (Eds.), Proceedings of the 28th Conference of the International Group for the Psychology of Mathematics Education (Vol. x, pp. 17-32). Bergen: Bergen University College.

Jaworski B. (2006). Theory and practice in mathematics teaching development: Critical inquiry as a mode of learning in teaching. Journal of Mathematics Teacher Education, 9(2), 187-211.

Jaworski, B. (2008). Development of the Mathematics Teacher Educator and its relation to Teaching Development. In B. Jaworski \& T. Wood (Eds), Volume 4 of the International Handbook of Mathematics Teacher Education, Mathematics Teacher Educator as a Developing Professional (pp. 335-361). The Netherlands: Sense Publishers.

Jaworski, B. (2011). Teaching mathematics to address fundamental human rights. Utrecht: Freudenthal Institute, University of Utrecht. 
Jaworski, B. \& Potari, D. (2009). Bridging the macro-micro divide: using an activity theory model to capture complexity in mathematics teaching and its development. Educational Studies in Mathematics. 72: 219-236.

Lerman, S. (1996). Intersubjectivity in mathematics learning: A challenge to the radical constructivist paradigm. Journal for Research in Mathematics Education, Vol 27, No 2. 133-150.

McIntyre, D. (1993). 'Theory, Theorizing and Reflection in Initial Teacher Education.’ In J. Calderhead and P. Gates (Eds.), Conceptualising Reflection in Teacher Development (pp. 39-52). London, Falmer.

Mason, J. ; Burton, L. \& Stacey, K. (1982). Developing Mathematical Thinking. London: Addison Wesley.

Nardi, E. \& Steward, S. (2003). Is mathematics T.I.R.E.D? A profile of quiet disaffection in the secondary mathematics classroom. British Educational Research Journal, 29, 3, 345-368.

Nolder, N. (1992). Bringing Teachers to the Centre of the Stage. Unpublished PhD Thesis, University of London, Kings College.

Open University (1988). ME234:Using Mathematical Thinking, Video Anthology. Milton Keynes: Open University.

Potari, D. \& Jaworski, B. (2002). Tackling Complexity in Mathematics Teacher Development: Using the teaching triad as a tool for reflection and enquiry. Journal of Mathematics Teacher Education, 5, 4 pp. 351-380.

Pring, R. (2004). Philosophy of Education. London: Continuum.

Sfard, A. \& Prusak, A. (2005). Telling identities: In search of an analytic tool for investigating learning as a culturally shaped activity. Educational Researcher, 34(4), 14-22.

Skott, J. (2001). The emerging practices of a novice teacher: The roles of his School Mathematics Images. Journal of Mathematics Teacher Education, 4, 1, 3-28.

Skovsmose, O. \& Säljö, R. (2008). Learning mathematics through inquiry. NOMAD, $13,31-51$.

Stenhouse, L. (1984). Evaluating curriculum evaluation. In C. Adelman (Ed.). The Politics and Ethics of Education. London: Croom Helm.

Sutherland, R. (2007). Teaching for learning mathematics. London: Open University Press.

Wenger, E. (1998). Communities of Practice: Learning, Meaning and Identity. Cambridge: Cambridge University Press.

Wells, G. (1999). Dialogic inquiry: Toward a sociocultural practice and theory of education. Cambridge, UK: Cambridge University Press

Wells, G (Ed.) (2001). Action, talk and text: Learning and teaching through inquiry. N.Y.: Teachers College Press.

Wilson, H. \& Goldenburg, M. P. (1998). Some conceptions are difficult to change: One middle school mathematics teacher's struggle. Journal of Mathematics Teacher Education, 1, 3,, 269-293.

Zack, V., Mousley, J. \& Breen, C. (1997). Developing practice: Teachers' inquiry and educational change. Victoria, Australia: Deakin University. 
Zaslavsky, O. \& Leikin, R. (2004). Professional development of mathematics teacher educators: growth through practice. Journal of Mathematics Teacher Education, \&, 1, 5-32.

Characters inc. spaces 67442 